Safety and Security Engineering VII 33

\title{
RASTER MAP SERVICES VIEWER FOR FLOOD RISK ANALYSIS AND ASSESSMENT
}

\author{
YOLANDA SOLÍS-ALVARADO, JAVIER ALEMÓN, MIGUEL MEDINA-GARCÍA, \\ JAVIER GARCÍA-HERNÁNDEZ \& HÉCTOR SANVICENTE-SÁNCHEZ \\ Subcoordination of Surface Hydrology, Mexican Institute of Water Technology, Mexico
}

\begin{abstract}
The Mexican Institute of Water Technology (IMTA, its Spanish acronym) has developed a geographical tool named Raster Map Services Viewer version 1.0, in order to publish flood zones in a public way for some return periods (Tr), mainly for $\operatorname{Tr} 2,5,10,50$ and 100 years, of some priority areas of the country. The application has the web address http://hidrosuperf.imta.mx/ anriconagua/ and at this web address it is possible to consult the map services of 13 pilot zones obtained by modelling made by the Institute of Engineering of the Autonomous University of Mexico (UNAM) and cost calculation made by IMTA in 2013, likewise 4 basin-cities generated (modelled and cost calculated) by IMTA in 2014. These map services were generated with the Geoserver tool, which is an open source server for sharing geospatial data. Each raster map service can have one of three variables: velocity, flood depth and cost (damage) per cell, which are queried by clicking on the cell of interest. The first raster map service contains flood depth per cell resulting from hydrological-hydraulic modelling made by a team of modelers from two institutions in Mexico (UNAM and IMTA); The second one has the velocity of the flow with which that flood depth was reached, and the last one has the costs in Mexican pesos per pixel estimated with the computational tool ANRI_Batch-PC v1.0. Raster Map Services Viewer version 1.0 also manages user and password to give maintenance to the site. The costs in Mexican pesos are far from accurate, however, they can be used as a reference parameter or indicator to have an idea of how critical the problem of flooding is in the selected area.

Keywords: raster map services, flood zones, return period, cost calculation.
\end{abstract}

\section{INTRODUCTION}

Hydraulic contingencies in the last decades have caused human, economic, social and environmental impacts of enormous importance for governments and populations. Some of the factors that provoke flooding are: Hurricanes and low-pressure systems, failure of protection structures, change of land use (from agricultural to urban), insufficient or nonexistent drainage, human settlements in federal zone, among others.

A problem derived from the above is the quantification of damages as well as the publishing of flooding zones for all people. To solve this problem the National Water Commission (CONAGUA) develops studies in order to reduce its consequences on the population and to define mitigation and response actions for the preparation, planning and management of emergencies, as well as propose public policies in regard to this. From the year 2013 to 2015, the Mexican Institute of Water Technology (IMTA) helped the CONAGUA to generate some intermediate products to carry out this assessment in some floodable areas, which were a result of such studies.

The website http://hidrosuperf.imta.mx/anriconagua/ hosts the raster map services viewer for flood risk analysis and assessment also known as ANRI-Conagua; it was developed as a pilot test to display some raster map services related to flood depth per cell, the velocity of the flow with which that flood depth was reached and the assessment of the costs. The raster map services viewer allows any Mexican citizen to know and analyse several recurrent flood zones in Mexico in order to make an informed decision on whether to settle in that potentially floodable area or not, and to the Mexican government authority as a support tool to guide 
public policy regarding flood protection works that must be prioritized for its implementation. National Center for Prevention of Disasters (CENAPRED) is the official institution in Mexico that publishes this kind of mapping services, not only for flood risk, but for any risk that affects the Mexican population. Since CENAPRED was born, it has been studying and publishing information about risks analysis through applications software in its computational platforms. One of these applications is the National Atlas of Flood Risk (ANRI, its Spanish acronym). So, the raster map services viewer was developed to test the services before including them into the CENAPRED platform.

\section{INPUTS AND VIEWER DEVELOPMENT}

The raster map services viewer manages three types of raster map services: velocity, flood depth and cost (damage) per cell. Let's see how those map services were obtained. Hydrological-hydraulic modelling was done by the Institute of Engineering of the Autonomous University of Mexico (UNAM) for 13 pilot zones during the year 2013 meanwhile IMTA was implementing the first version of a methodology to estimate costs in flood zones. During the year 2014, IMTA modelled 4 basin-cities using Iber software [1] and applied the methodology studied during 2013 and implemented in the National Atlas of Flood Risk for batch processing program running on Personal Computer platform (ANRIBatch_PC v 1.0) (Fig. 1), with which the economic damages (costs) were calculated for those cities-basin. In the year 2015 IMTA processed (modelling and damage assessment) more than 20 basin-cities. Most of the basin-cities were modelled with Iber software and a couple of them with Mike Flood software. The result of this modelling was the velocity and flood depth per cell in the flood zone. IMTA developed programs to extract/convert Iber points into shapes (points shapes), of velocity and flood depth variables.

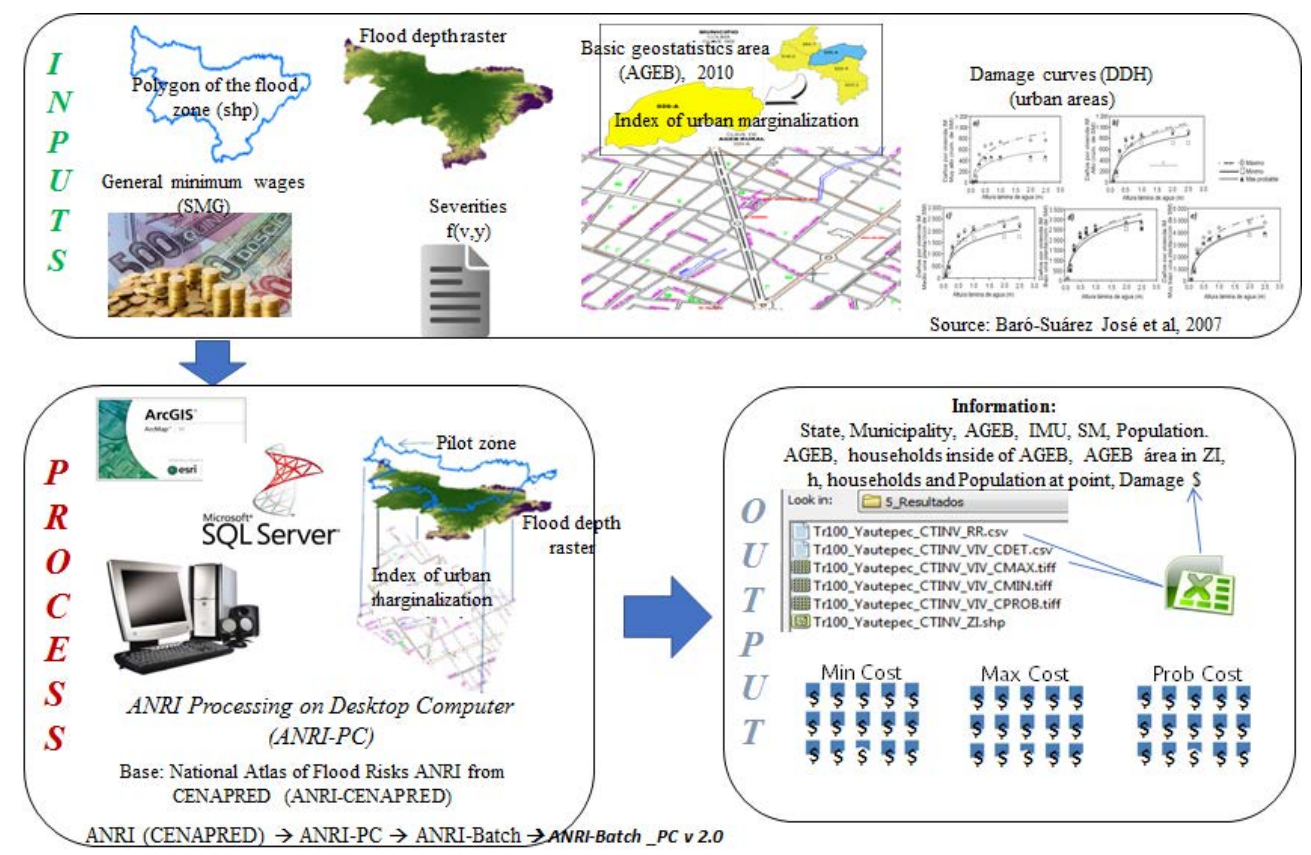

Figure 1: Methodology used by ANRI-Batch_PC v 2.0 to estimate economic costs in a flood zone. 
Regarding the costs, they were obtained through ANRI_Batch PC, in its three versions (zero, 1.0 and 2.0), whose differences are the use of basic geostatistics area (AGEB, its Spanish acronym) versus blocks (speaking in terms of cadastre). The use of one or other version impacts the accuracy of the calculation. In summary, the ANRI methodology for damage estimation in floodable urban areas [2], [3], consists of crossing the flood depth with the urban marginalization index [4], (Fig. 1), better known as IMU (from AGEB) which means how many and what kind of housing content is in all the houses existing inside the AGEB. Then applying the Baró vulnerability curves [5], to get the amount of direct housing damage (DDH, its Spanish acronym) in units of General Minimum Salaries.

In other words, for each pixel we have two variables: flood depth (from modelling) and urban marginalization index (from AGEB). Both variables enter to the vulnerability curves [5], to get the amount of housing damage in units of minimum salaries. Immediately, we convert DDH to pesos according to the value of the minimum salary in Mexico, which changes each year.

At this point, we have a raster map for flood depth, a raster map for velocity and three raster maps for costs (minimum, maximum and more probability cost). Then we use the Geoserver tool to generate each raster map service, meaning that the website consults the geoserver in real time using a selection menu that shows the layers that are available at the moment.

The raster map services viewer was developed to work on Windows Server 2008 R2 Standard using html language (HyperText Markup Language) with CSS sheets (Cascading Style Sheets), JavaScript language with JQuery and OpenLayer libraries, Google Maps API v3 to create the map base, and Web Services Aspx.Net (C\#). Besides, it uses three servers: Geoserver 2.5.2 (it's an open source server for sharing geospatial data), Internet Information Services 7.5 (IIS 7.5) (it's the web server) and SQL Server 2008 R2 (it's the database server).

\section{VIEWER INTERFACE}

The process that follows the ANRI-Conagua to query the values of each cell of the raster map services is the following. The website consults the geoserver in real time using a selection menu that shows the layers that are available at the moment, then the request is made to the Web server (IIS), followed by it passing to the geographic server and returning the requested layer. The website having the response layer shows in the web browser using Openlayer code that allows the manipulation of geographic layers on the client side (web browser), the geographical layer is overlaying on a map of Google Maps as the base map (allowing to change between satellite, topographic, roads), with the layer on the base map. You can consult attributes of the layers at the point where you click on the map.

The structure of the homepage is divided into four regions, namely: Header, displays the title of the application and a button to register the users of Conagua that have valid user and password; Menu, displays menu options; Work area, This region is located on the left side and is used to mainly show controls for layers, options for tools and information for layer values; and, Map, This is the main region of the application, here the base maps and the layers with the information concerning the risks by flood are presented.

The viewer interface consists basically of four menus (Figs 2(a),(b), (c) and (d)): maps (mapas), shapes (capas), Tools (Herramientas) and Help (Ayuda). Below we will explain each of the menu options offered for general users. 
3.1 Maps (Mapas) menu

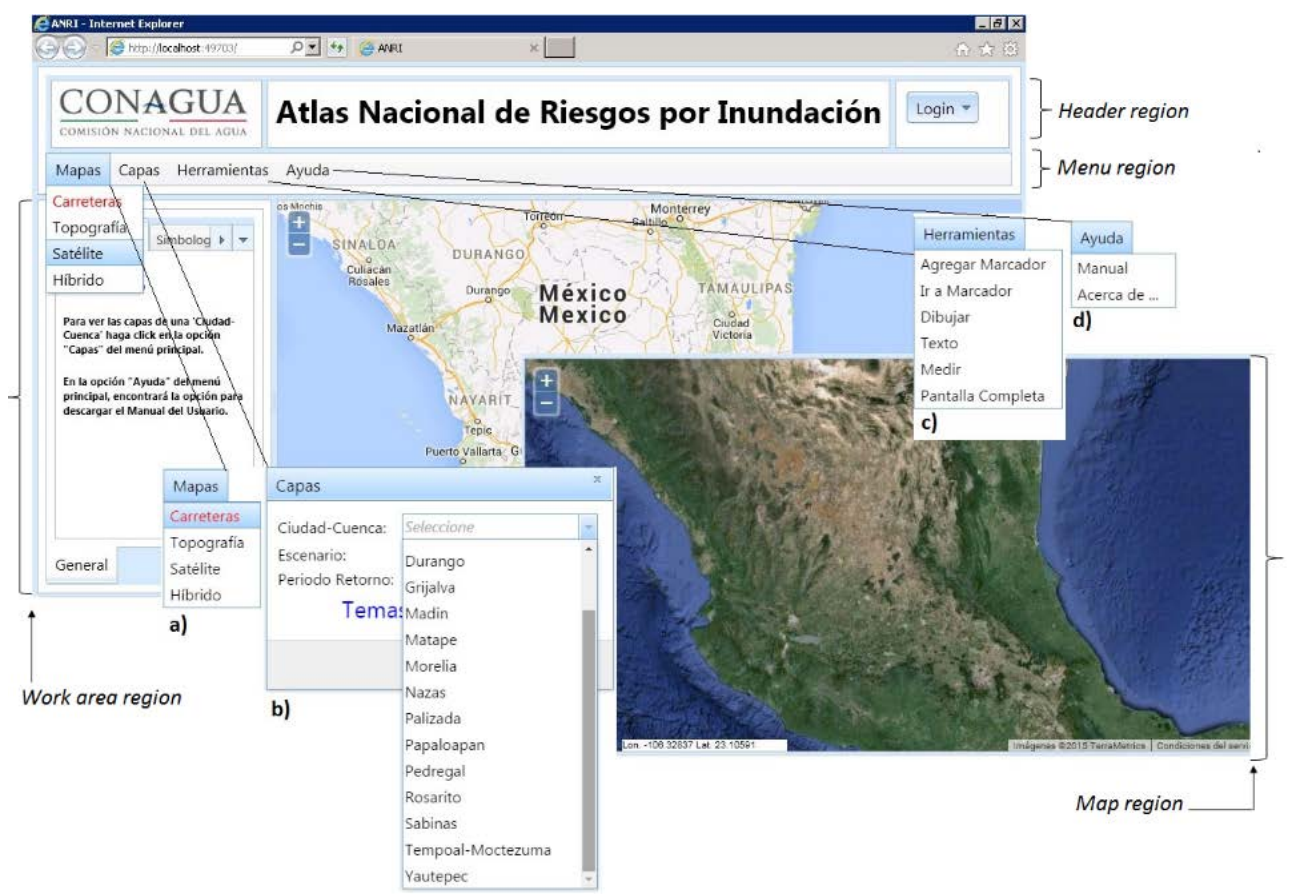

Figure 2: Main screen of raster map services viewer, its menus and its base maps.

This option allows you to change the base map, at the start point the map "Roads" is presented but it can be changed to: "Topography", "Satellite" or "Hybrid", Fig. 2 shows "Roads" and "Satellite" maps, all the base maps that are presented are the ones that Google offers to the general public.

\subsection{Shape (Capas) menu}

This option menu is the core of the ANRI-Conagua. With this menu, you will be able to choose the information regarding the Data on Flood Risks that are produced by Conagua and IMTA. When you select this option, a dialog appears for choosing the name of the city-basin (Fig. 3, Section (a), the scenery modelled (either actual conditions or modified conditions) and return period (Tr) for you to choose the information you want to query (Fig. 3, Section (b) and (c)). Once you have chosen the $\mathrm{Tr}$, the viewer will present the topics that are available to you. In this example (Fig. 3, Section (b), the city-basin selected is Rosarito, which was modelled in actual conditions, Tr equal to 100 years, and the available raster map services or layers are flooding zone, severities, flood depth and velocity. Finally, you must press the "Aceptar" button to be presented with the necessary controls to handle the selected layers. The viewer will inform to you if the process was successful. 


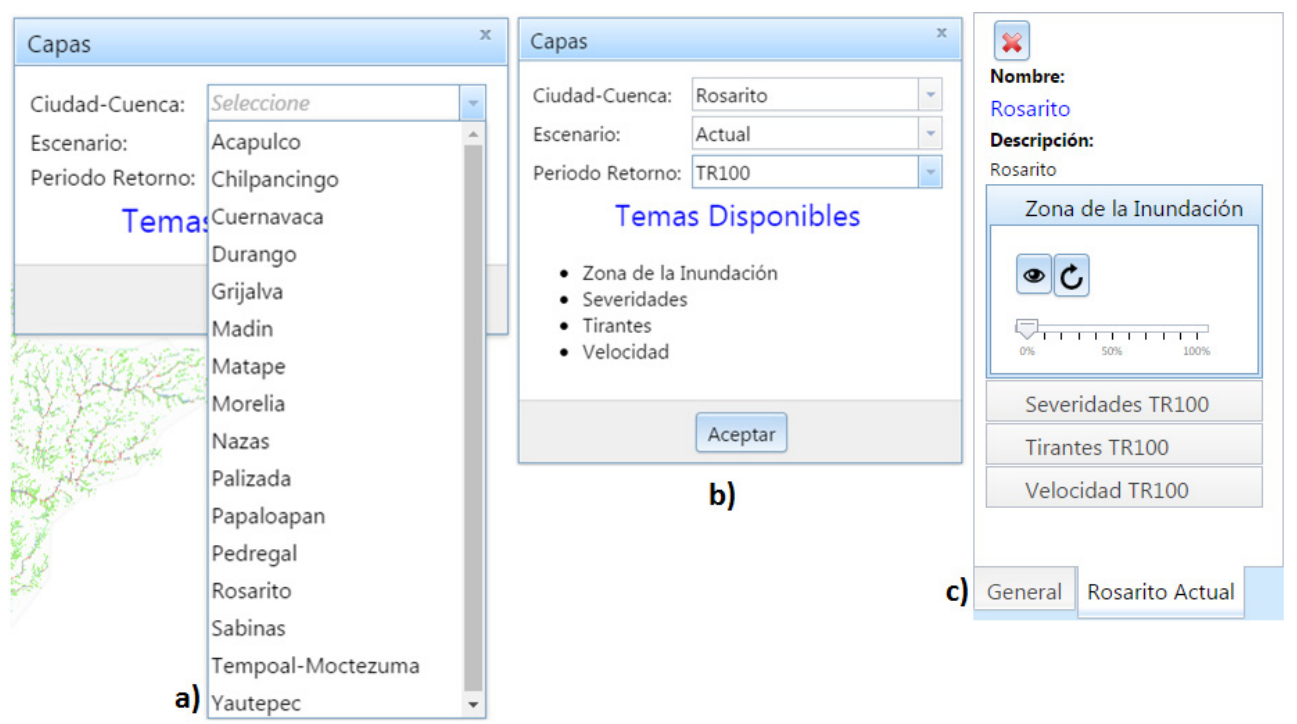

Figure 3: Shapes (Capas) menu of raster map services viewer.

In the work area, the Name and Description of the chosen City-Basin and the Flood Zone controls are displayed (Fig. 3, Section (c). The control allows you to view the layer and move the basemap to the region where the layer information is located. There is also the control to hide or redisplay the layer. The other control you have is to indicate the level of transparency of the layer. To access the controls of the other layers, just click on the name of the layer. The layer controls are now displayed so you can view them (Fig. 4).

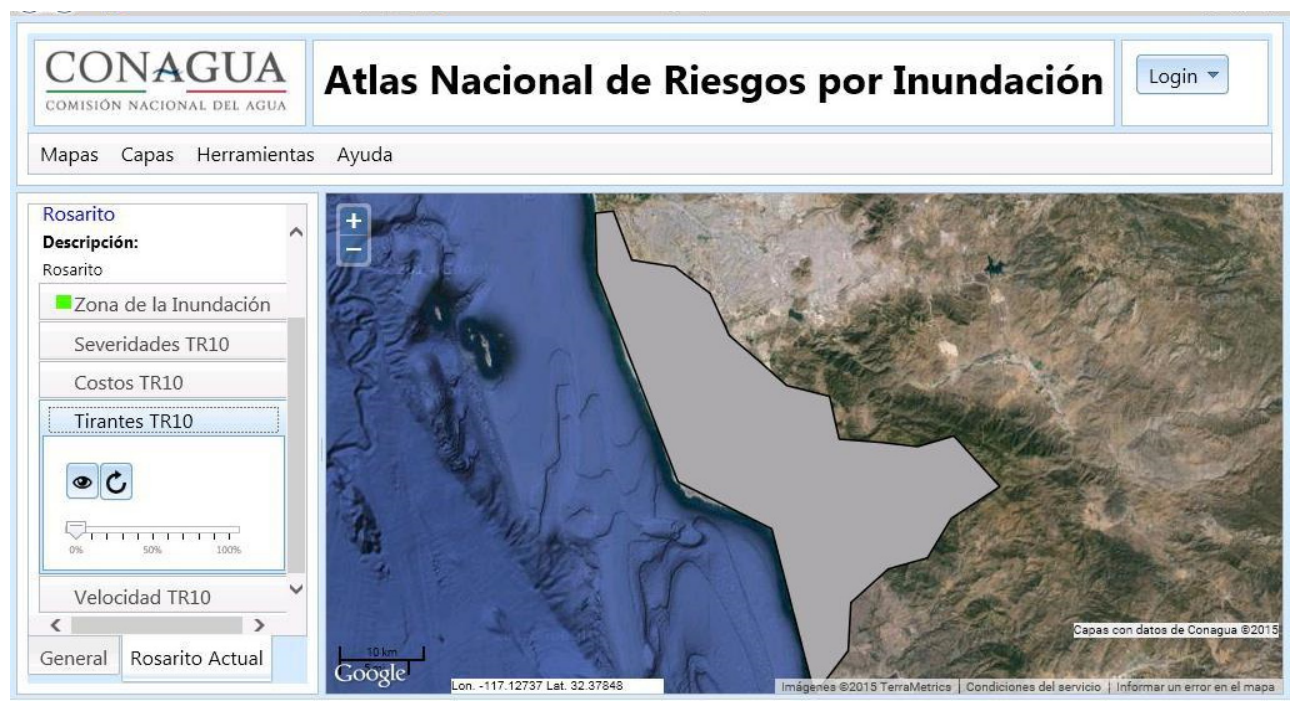

Figure 4: Example of available layers of the city-basin Rosarito: flood zone, severities, costs, flood depth and velocity. 
To see the controls of the layers, simply choose the tab with the name of the city-basin. Note that the layers that are visible are marked with a small green box. In the example, the green box is observed for flood zone shape ("Zona de inundación" tab) (Fig. 4).

On the other hand, you can query the value in each pixel (Fig. 5, Section (a)) of the layer or layers that are shown on the map; To do so, it is enough to click on a point of the layer. To do this, the most recommended action is to zoom the map. The control (+ -) in the top left corner of the map is used to zoom out (-) or zoom in (+). You can also move the map by dragging with the mouse. You could click on the symbology tab (Fig. 6) and choose the severity, flood depth, velocity or costs tab. Each of them has its own color palette.

Note that in the work area the values of the layers are shown at the point where they are clicked. If you wish, you can have more layers corresponding to other cities-basin (Fig. 5, Section (c)); To do this, click the "Loaded city-basin" button (Fig. 5, Section (c)) and perform the procedure described above. If you choose the layers of the same cities-basin and scenery, but with different Tr, then the controls of the layers will be in the same tab (Fig. 5, Section (b)).

If you choose a different city-basin or another scenery, then the controls of the layers are presented in another tab (Fig. 6, Section (c)). To finish this part, it is necessary to explain the use of the erase button ( ), which is used to remove the tab and its corresponding layers. The viewer will ask you to confirm your request.

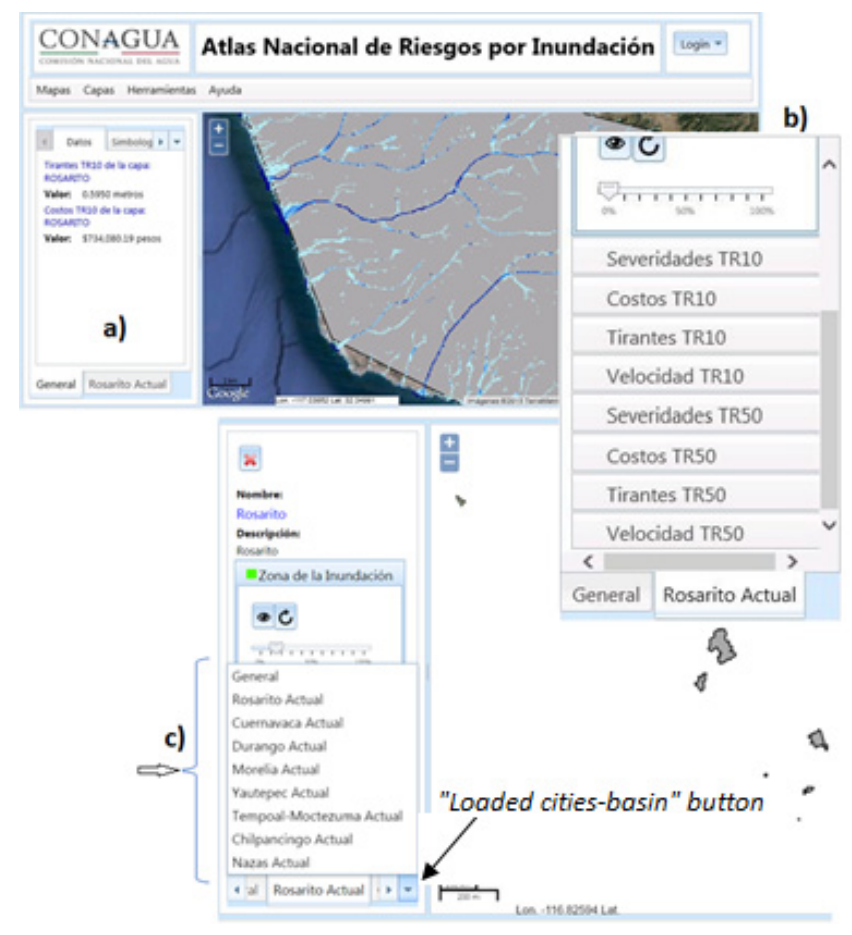

Figure 5: Example of (a) querying the value of flood depth in a pixel; (b) Layers of the same city-basin and scenery but different Tr; and (c) City-basin loaded in the same session. 

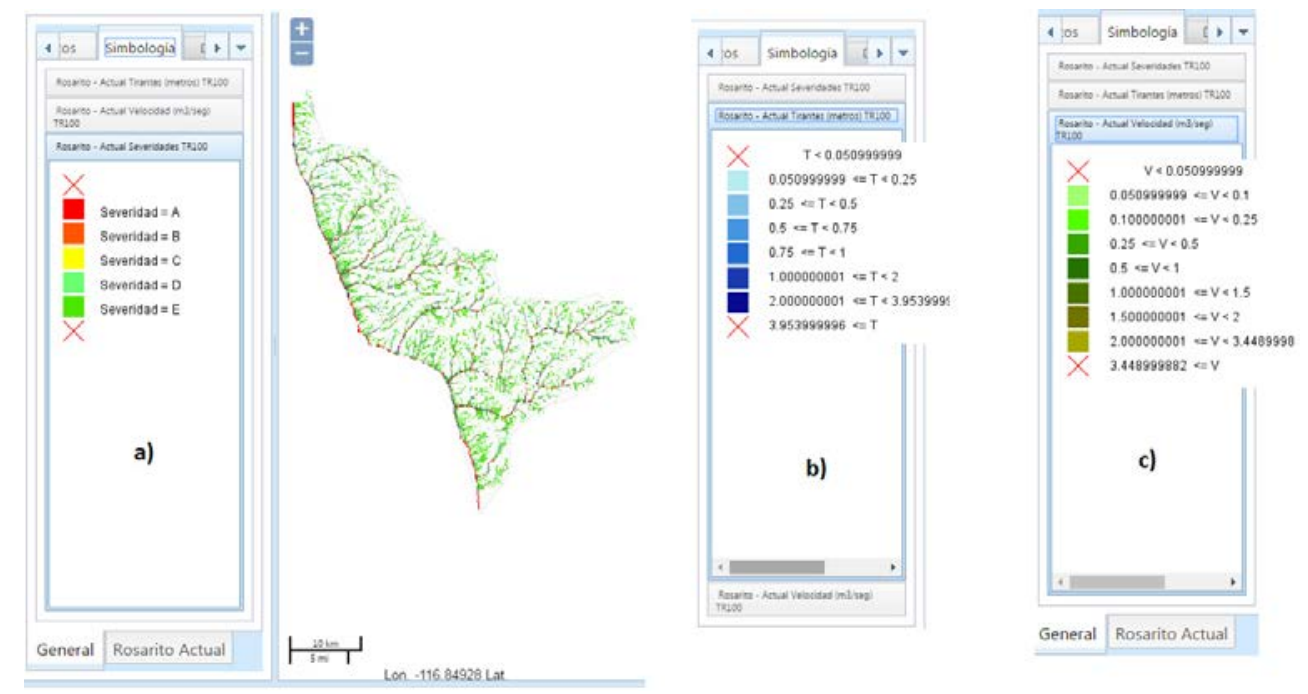

Figure 6: Example of different color palette for each variable: (a) Severity; (b) Flood depth; and (c) Velocity.

\subsection{Tools (Herramientas) menu}

In this menu option you have the following tools: Add Marker (Agregar marcador), Go to Marker (Ir a marcador), Draw (Dibujar), Text (Texto), Measure (Medir), Full Screen (Pantalla completa) (Fig. 2, Section (c)). Let's see how to use these tools.

Add Marker (Agregar marcador). A "Marker" represents the position and level of approach you have at any given time on the map; this is similar to the position mark option from Google Earth. So, to add this marker simply provide the "Description" for the marker and click on the "Add" button. Once this is done, the new marker appears immediately in the current marker table. It is important to note that the registered markers are preserved in memory; So, when you close the raster map services viewer, those are deleted.

Go to Marker (Ir a marcador). With this option you can move the map to one of the current bookmarks you have registered. Selecting this option displays the list of existing labels. To move the map to one of them simply click the bookmark button.

Draw (Dibujar). This option allows you to draw some geometric elements. This is done in a virtual separate layer of the other layers we are working on, we can draw upon the base map or the layers of the city-basin already loaded but just in a visual way. Choosing this option five radio buttons appears in the work area with the options (Fig. 7): draw a point, a line (path), a polygon or a box (rectangle); you must choose one of the options that appear in that work area. The mechanics for drawing are the following: Point. Choose the "Point" option and click on the map where you want the point to appear. Line. Choose the "Line" option and start drawing the line by clicking on the map; Then move the mouse pointer to where you want the line to end. To end the line, double-click; But if you are drawing a path, then click and continue drawing. Polygon. Choose the "Polygon" option and click on the map in the place where you want the first vertex of the polygon; Move the pointer to the place where you want the second vertex to be drawn; Continue drawing the other vertices and when you want to finish, then double-click, the polygon will be close in automatic way. Box. 


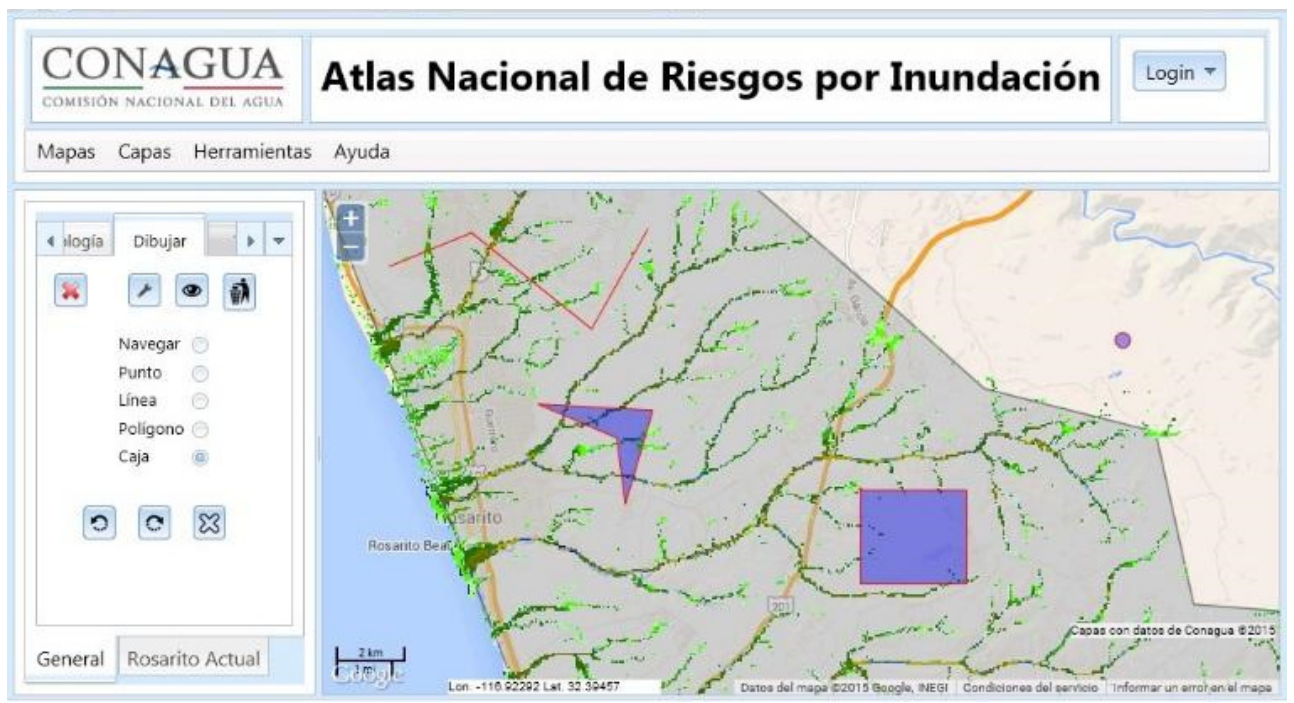

Figure 7: Options to draw geometrics figures upon the raster map services to highlight some areas of interest.

Choose the "Box" option and press the left button at the point where you want the first vertex of the rectangle to be; Holding down the left mouse button move it to draw the required rectangle. To end the rectangle, release the left mouse button. Browse. This option is used to inhibit any of the other options, so you can perform other actions involving the mouse.

The buttons $Ð$ and $§$ (Fig. 7 and Fig. 8, Section (a)) are used only when drawing a line or a polygon; And its function is as follows: $\operatorname{Undo}(\%)$, removes the last line drawn from the trajectory or the last drawn side of the polygon. Redo (C), redraw what was undone.

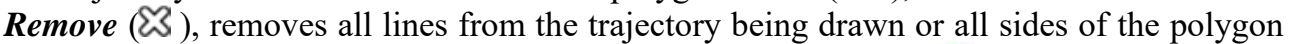
being drawn. The buttons at the top of the work area are used to: $₹$ Disable the Draw tab and hide the layer, it does not delete what you have drawn. It presents the dialog to configure the style of the elements that are drawn (Fig. 8, Section (a)). 0 Hides the drawing layer or visualizes it, depending on what option is active. 햅 Remove everything that has been drawn, but first asks to confirm the action.

Text (Texto). (Fig. 8, Section (b)). This tool is used to draw texts in a layer used exclusively for it. To draw a text, you must provide it and an anchor point in which to draw. To provide the coordinates of the point, simply click on the map where you want the text to appear. Once you have provided all the data you should press the button: $\odot$ (Add). The text is drawn by having the anchor point in the lower left of the first character of the text to be drawn. If you want to change the position of the text, you must indicate a new point and press the button: (Refresh). To change the text, you must change it and press the "Update" button. To remove the last drawn text, you must press the button: $\Theta$ (Remove). If you press this button again, then the penultimate text drawn will be removed; and so on.

Measure (Medir). You can measure either "Measure Distance" or "Measure Area"; draw the path or polygon. While you are drawing, the measurement value is displayed in the work area. Double-click to finish drawing. If you start another measurement, you will lose the value of the previous measurement. By default, the distance or area calculation is made in 


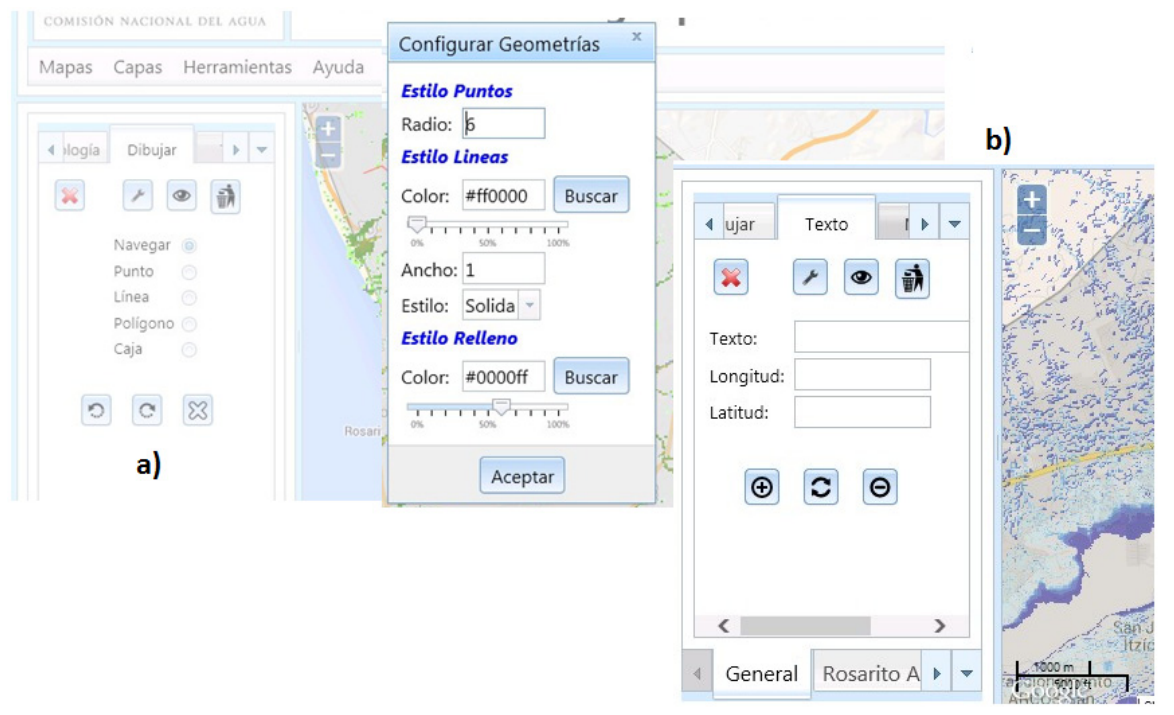

Figure 8: Options to: (a) Configure geometries in the Draw tool; and (b) To draw texts in a layer in the Text tool.

the map plane; That is, with coordinates in the projection known as Google Web Mercator. If you want a more accurate calculation, then choose the option: "Use Geodetic Measurement" to be performed using geographic coordinates.

The "Browse" option is used to inhibit any of the other options, so you can perform other actions involving the mouse. And finally, the button $\approx$ disables the tab to measure.

Full Screen (Pantalla completa). With this option you can see the map in full screen. To return to the original view press the "Esc" key. Here, you do not have all the functionality that is available in the original view, but you can move the map, zoom out and zoom in, and with the control on the left side of the map, you can choose which base map is displayed and which layers are visible; Including the "Draw" and "Text" layers.

\subsection{Help (Ayuda) menu}

In this option you have two possible choices. The first, called "Manual" allows you to download the user manual, as a pdf file; and the second shows a screen which displays the credits of this application.

\section{CONCLUSIONS}

We have a free tool which easily publishes Raster Map Services containing three variables: velocity, flood depth and cost (damage) per cell for many floodable zones in Mexico, which are queried by clicking on the cell of interest. This is for all people but mainly to Mexican citizens in order to be used to make an informed decision on whether to settle in that potentially floodable area or not, but mainly as a support tool to guide public policy regarding flood protection works that must be prioritized for its implementation. Its importance lies in that it was the base for generating the official map services for flood risk analysis and assessment published by CENAPRED. 


\section{ACKNOWLEDGEMENTS}

To the Engineering Institute of the UNAM for providing results of its modelling for 13 pilot zones (speed and depth variables). To the Management of Superficial Water and River Engineering of the National Water Commission for being the counterpart that contracted the project. And to all the support personnel who were responsible of running the ANRIBatch_PC v 0, v 1.0 and v 2.0.

\section{REFERENCES}

[1] Iber model, a two-dimensional software for the simulation of free surface flow, morphodynamics and transport processes in rivers and estuaries; Universitat Politécnica de Catalunya, Online, http://iberaula.es/web/index.php. Accessed on: 7 Jul. 2017.

[2] Solís-Alvarado, Y., Lafragua-Contreras J. \& García-Hernández J., Estimación del daño anual esperado en zonas urbanas inundables. Presented at 2nd International Congress on Plains Hidrology, Santa Fe, Argentina, 2014.

[3] Solís-Alvarado, Y., Sistema para estimación de daños económicos por inundación en zonas urbanas. Presented at XXII Congreso Nacional de Hidráulica, Puerto Vallarta, Jalisco, México, 2014.

[4] Urban cartography; National Institute of Statistics and Cartography (INEGI), Online, http://www.inegi.org.mx/geo/contenidos/urbana/. Accessed on: 30 Jan. 2014.

[5] Baró-Suárez, J.E., Díaz-Delgado, C., Calderón-Aragón, G., Cadena-Vargas, E. \& Esteller-Alberich, M.V., Costo más probable de daños por inundación en zonas habitacionales de México. Tecnología y Ciencias del Agua, before Ingeniería Hidráulica en México, volumen II, núm. 3, julio-septiembre de, pp. 201-218, 2011. 